\title{
NEVUS MELANOSITIK KONGENITAL LUAS LAPORAN KASUS DAN TELAAH LITERATUR
}

\author{
Stella Sjambali, Shinta Rahmayani, Yohanes Widodo Wirohadidjojo, Retno Danarti \\ Departemen Dermatologi \& Venereologi, \\ FK Universitas Gadjah Mada RSUP Dr. Sardjito Yogyakarta
}

\begin{abstract}
ABSTRAK
Nevus melanositik kongenital (NMK) atau giant congenital melanocytic nevus merupakan nevus yang muncul saat lahir atau timbul beberapa minggu pertama kehidupan. Lesi dengan ukuran besar dapat menimbulkan masalah psikososial dan meningkatkan risiko melanoma maligna (MM). Bila didapatkan di daerah kepala dan leher disertai nevus satelit perlu dipikirkan kemungkinan neurokutaneus melanosis (NM). Data rekam medis poliklinik Kulit dan Kelamin RSUP Dr. Sardjito periode Januari 2009-Desember 2017 didapatkan 12 kasus NMK luas.

Pada makalah ini dilaporkan seorang anak perempuan berusia 5 tahun yang sejak lahir didapatkan bercak hiperpigmentasi-keabuan, sebagian disertai hipertrikosis, multipel, berukuran $10 \mathrm{~cm}$ hingga $>20 \mathrm{~cm}$ pada telinga kiri hingga leher kiri dan tengkuk, serta bokong. Sejak usia 2 tahun muncul lesi berukuran lebih kecil berupa makula hingga bercak hiperpigmentasi multipel di wajah, kedua lengan, tungkai, punggung, telapak kaki, dan punggung kaki. Tidak terdapat perubahan ukuran lesi yang cepat, kejang, nyeri kepala, maupun muntah berulang. Pada pemeriksaan computed electroenchepalograph (CEEG) dan brain mapping (BM) tidak ditemukan gelombang epileptiform, namun ditemukan perlambatan difus background activity, oleh karena itu disarankan pemeriksaan CT-scan kepala. Pasien ini didiagnosis nevus melanositik kongenital luas.

Nevus melanositik kongenital luas dapat meningkatkan risiko terjadinya MM dan bila berlokasi di sepanjang aksis posterior disertai lesi satelit berisiko berkembangnya NM, yaitu sindrom dengan proliferasi melanosit pada sistem saraf pusat disertai NMK. Pada kasus ini tidak didapatkan gejala NM secara klinis namun pelacakan untuk NM dan observasi terhadap MM perlu dilakukan.
\end{abstract}

Kata kunci : nevus melanositik kongenital luas, neurokutaneus melanosis

\section{GIANT CONGENITAL MELANOCYTIK NEVUS: CASE REPORT AND LITERATURE REVIEW}

\section{Korespondensi:}

Dr. Med. dr. Retno Danarti, SpKK(K)

Departemen Dermatologi dan Venereologi, Fakultas Kedokteran UGM

Gedung Radiopoetro 1t 3, Jalan Farmako

Sekip, Yogyakarta 55281

\section{ABSTRACT}

Congenital melanocytic nevus (CMN) is a nevus which presents at birth or arises within the first few weeks of life. Large or giant lesions (LCMN, GCMN) can cause a devastating psychosocial burden and increase the risks of malignant melanoma (MM). LCMN found on scalp and neck accompanied with satellite nevi has a tendency to develop neurocutaneous melanosis (NM). From medical records outpatients clinic Dermatology \& Venereology Dr. Sardjito hospital from January 2009 - December 2017 we found 12 cases of LCMN.

A five-year-old girl developed multiple grayish-hyperpigmentation patches since born. Some lesions on her left ear to nape and buttock were associated with hypertrichosis. Its size ranged from $10 \mathrm{~cm}$ to $20 \mathrm{~cm}$. Since age 2 years old, smaller lesions appeared with multiple hyperpigmentation macules and patches on her face, both arms and legs, back, dorsal feet and soles. The patient had no history of seizure, headache, and vomite. Computed electroenchepalograph and brain mapping examinations revealed no epileptiform wave, however delayed diffuse background activity was found. We have planned to do scalp computed tomography scan, but the patient refused. We diagnosed the patient as having large congenital melanocytic nevi.

Large congenital melanocytic nevi have a great chance to differentiate to malignant melanoma. Lesions located along posterior axis accompanied with satellite lesion have greater risk of developing neurocutaneous melanosis, a syndrome which occurs from melanocytic proliferation in central nervous system associated with congenital melanocytic nevi. In our case, clinical symptoms of neurocutaneous melanosis was not found, however the possibility to develop neurocutaneous melanosis and malignant melanoma must be followed up.

Key word: Large congenital melanocytic nevus, neurocutaneous melanosis 


\section{PENDAHULUAN}

Nevus melanositik kongenital (NMK) merupakan nevus yang mucul saat lahir atau beberapa minggu pertama kehidupan. Kebanyakan NMK berwarna kecoklatan, meskipun warna kehitaman dan keabuan hingga kebiruan dapat ditemukan. ${ }^{1}$ Sekitar $75 \%$ kasus ditemukan hipertrikosis di atas nevus. ${ }^{2}$ Ukuran NMK bervariasi mulai dari kecil hingga luas. Lesi dengan ukuran kecil kebanyakan tanpa gejala namun lesi dengan ukuran luas dapat menimbulkan masalah psikososial dan meningkatkan risiko kejadian melanoma maligna. Distribusi NMK ditemukan sebanyak $38 \%$ pada badan, $38 \%$ pada lengan dan tungkai, $14 \%$ pada kepala dan leher, $10 \%$ pada kaki dan tangan, dan $3 \%$ dengan distribusi multipel. ${ }^{2}$

Nevus melanositik kongenital berukuran luas terutama di daerah kepala dan leher yang disertai nevus satelit dapat dihubungkan dengan terjadinya neurokutaneus melanosis. ${ }^{3,4}$ Neurokutaneus melanosis simptomatik jarang ditemukan dengan prognosis yang buruk dibandingkan dengan neurokutaneus melanosis asimtomatik. ${ }^{5}$

Data rekam medis poliklinik Kulit dan Kelamin RSUP Dr. Sardjito periode Januari 2009 - Desember 2017, mendapatkan 12 kasus nevus melanositik kongenital luas (NMKL), terdiri atas 7 perempuan dan 5 laki-laki berusia antara 1 hari - 4 tahun, dengan lokasi terbanyak di area badan. Dari semua pasien tersebut tidak didapatkan pasien dengan NM dan tidak ditemukan kecenderungan kearah MM. Masih perlu pengamatan jangka panjang. Pada makalah ini dilaporkan satu kasus NMKL dengan tujuan untuk menambah wawasan mengenai NMKL dan menekankan perlunya pengawasan risiko yang mungkin terjadi pada NMKL.

\section{KASUS}

Seorang anak perempuan berusia 5 tahun datang ke poliklinik Kulit dan Kelamin RSUP Dr. Sardjito dengan keluhan tanda lahir yang luas pada leher dan bokong. Sejak lahir terdapat bercak berwarna kehitaman di telinga kiri hingga leher bagian kiri dan tengkuk serta bokong, yang di atasnya ditumbuhi rambut. Tanda lahir tidak bertambah luas. Saat berusia 2 tahun mulai muncul tahi lalat dengan ukuran lebih kecil di wajah, kedua lengan dan tungkai, punggung, telapak kaki, dan punggung kaki. Tahi lalat tersebut dirasa bertambah banyak. Pasien kemudian diperiksakan ke dokter spesialis Kulit $\&$ Kelamin di RS di Surakarta dan dikatakan sejenis "andeng-andeng". Biopsi jaringan pada lesi kehitaman telah dilakukan namun hasil biopsi tidak dapat dilacak karena data rekam medis sudah tidak bisa diakses. Pasien telah mendapatkan terapi laser sebanyak enam kali dengan hasil lesi kehitaman sebagian telah memudar namun sebagian menetap sehingga orang tua pasien memutuskan untuk berobat ke poliklinik Kulit \& Kelamin RSUP Dr. Sardjito. Orangtua menyatakan ukuran tidak bertambah besar yang cepat, bentuk lesi tidak berubah, tidak ada riwayat kejang, nyeri kepala, dan muntah berulang.

Pasien merupakan anak yang aktif dan tidak pernah tinggal kelas. Pasien adalah anak kedua dari dua bersaudara, lahir secara sectio caesaria karena persalinan tidak maju dengan berat badan lahir 3000 gram. Tidak ada hubungan saudara antara ayah dan ibu. Tidak ada kelainan serupa pada anggota keluarga pasien. Pedigree dapat dilihat pada gambar 1.

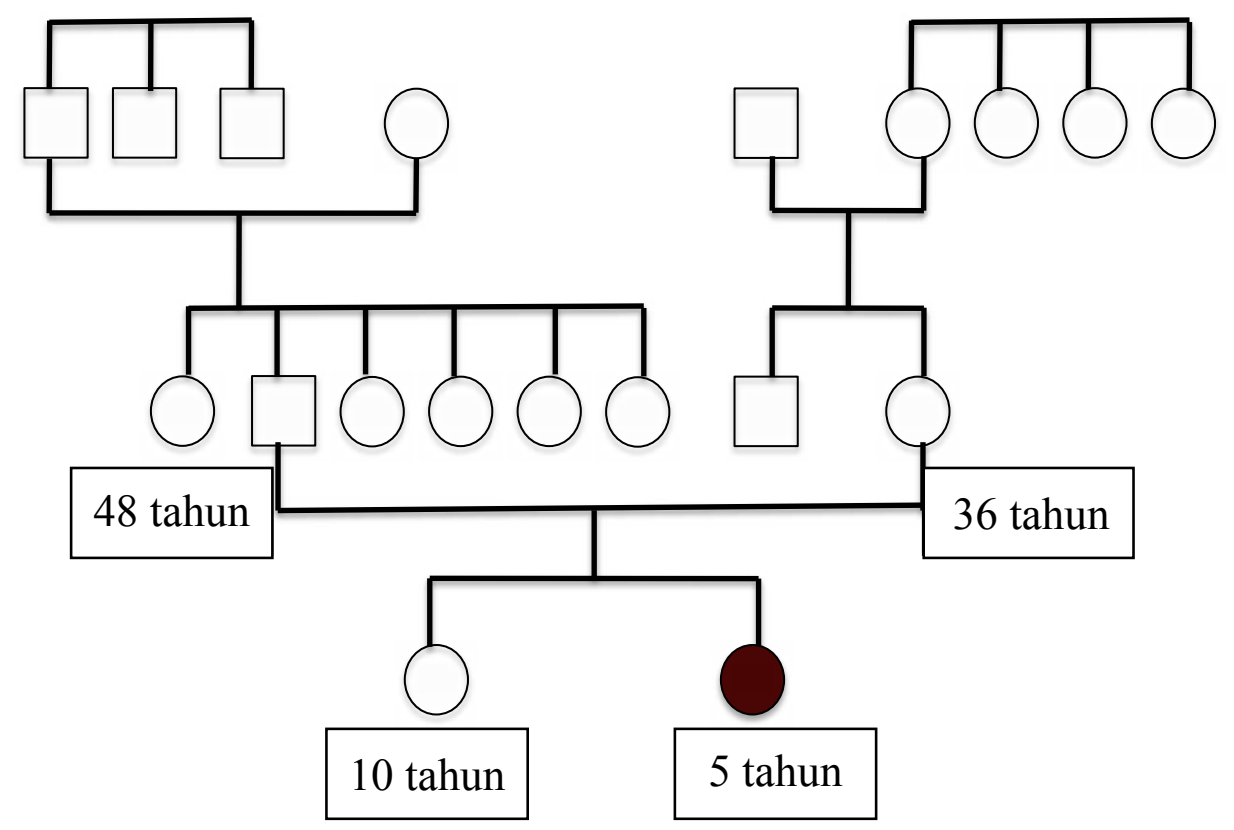

Gambar 1. Pedigree 
Pada pemeriksaan fisis didapatkan keadaan umum baik, kesadaran compos mentis, status gizi baik, tanda vital dalam batas normal. Status dermatologis pada telinga kiri hingga leher bagian kiri dan tengkuk serta bokong tampak bercak hiperpigmentasi hingga keabuan, berbatas tegas, multipel, diskret, ukuran bervariasi dari $10 \mathrm{~cm}$ hingga $>20 \mathrm{~cm}$, sebagian dengan bercak kecoklatan di tengahnya dan hipertrikosis di atasnya. Pada wajah, kedua lengan dan tungkai, punggung, telapak kaki dan punggung kaki tampak makula hingga bercak hiperpigmentasi, batas tegas, diameter bervariasi 0,3 hingga $5 \mathrm{~cm}$, multipel, diskret (Gambar 2-4). Berdasarkan anamnesis dan pemeriksaan fisis, diagnosis banding yang diajukan adalah nevus melanositik kongenital luas dan neurokutaneus melanosis.

Hasil pemeriksaan computed electroenchepalograph (CEEG) dan brain mapping (BM) tidak ditemukan gelombang epileptiform, namun terdapat gambaran perlambatan difus background activity. CT-Scan kepala telah disarankan namun orangtua pasien menolak. Berdasarkan anamnesis, pemeriksaan fisik dan pemeriksaan penunjang, diagnosis kerja yang diajukan pada pasien ini adalah nevus melanositik kongenital luas. Pasien tidak datang kembali untuk kontrol, sehingga perjalanan penyakit pasien tidak dapat diketahui.

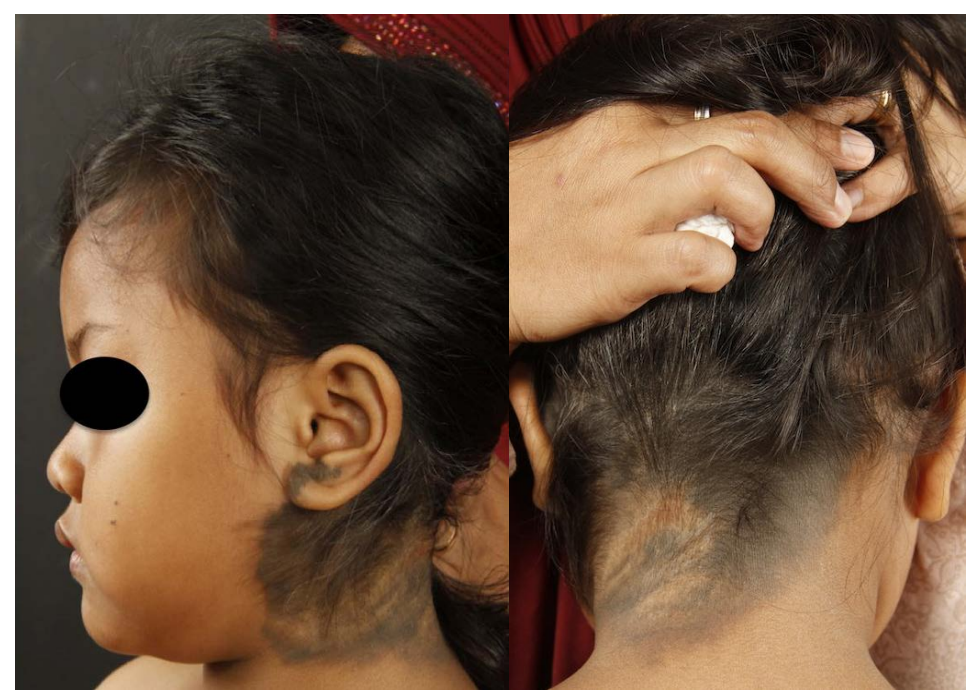

Gambar 2. Pada telinga kiri hingga leher bagian kiri dan tengkuk.

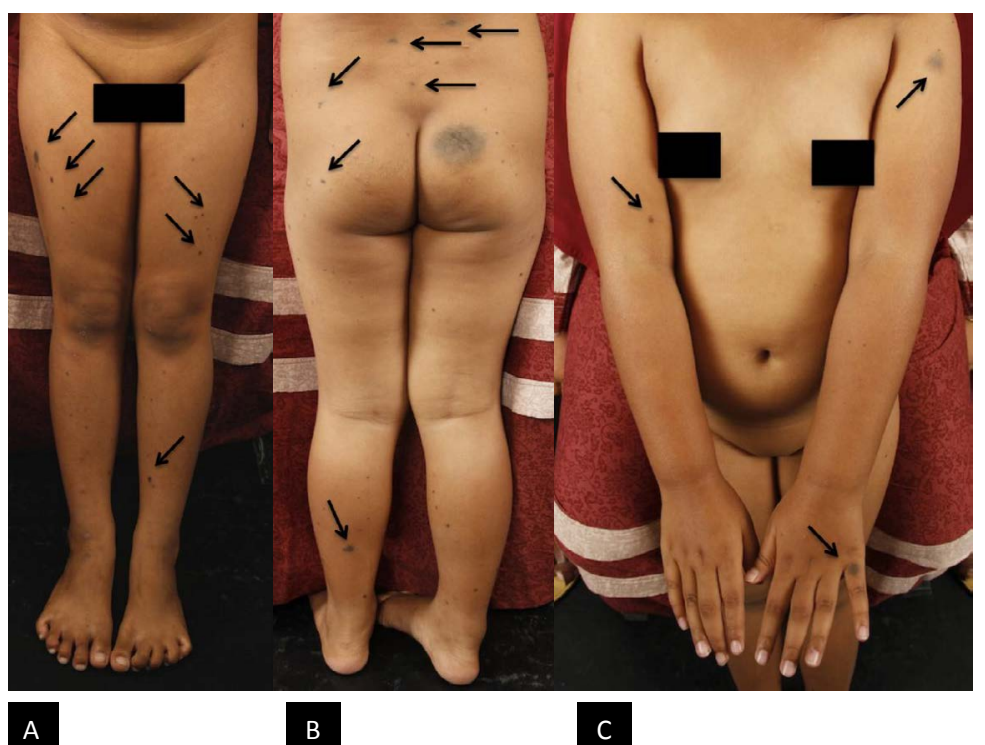

Gambar 3A-C Pada tungkai dan lengan tampak makula hiperpigmentasi berbatas tegas, multipel, diskret, bentuk bulat hingga oval,ukuran bervariasi dari $0,3 \mathrm{~cm}$ hingga $0,5 \mathrm{~cm}$ (lesi satelit). Pada bokong tampak bercak hiperpigmentasi hingga keabuan berbatas tegas, multipel, diskret, ukuran $6 \mathrm{~cm}$ dengan hipertrikosis di atasnya. Terdapat lesi satelit berupa makula hiperpigmentasi, berbatas tegas, multipel, diskret, ukuran bervariasi dari 0,3 hingga $0,5 \mathrm{~cm}$. Keterangan: tanda panah menunjukkan lesi satelit. 


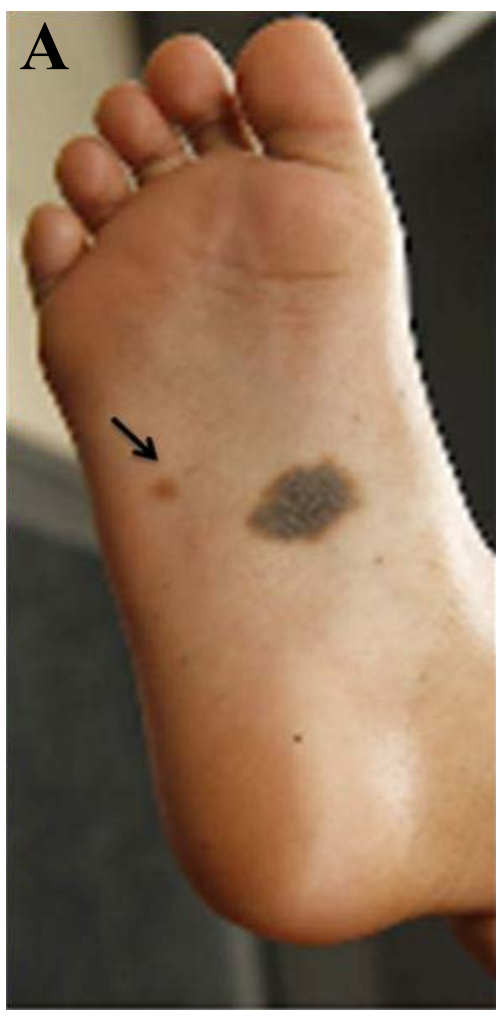

Gambar 4. Pada telapak kaki kanan tampak plak hiperpigmentasi ukuran $2 \times 3 \mathrm{~cm}$, soliter, dengan makula hiperpigmentasi ukuran bervariasi 0,2 hingga $0,4 \mathrm{~cm}$, multipel, tersebar.

\section{PEMBAHASAN}

Nevus melanositik kongenital luas pertama kali ditemukan oleh Reed pada tahun 1897. Kelainan ini sering dihubungkan dengan pertumbuhan melanositik jinak yang disebut dengan nodus proliferasi. ${ }^{2}$ Nodus proliferasi sering dikaitkan dengan nevus satelit berukuran lebih kecil dan dapat dijumpai pada saat lahir atau beberapa bulan hingga tahun berikutnya. Prevalensi NMK bervariasi antara $0,5 \%$ hingga $31,7 \%$ dengan diameter tersering kurang dari 3 hingga $4 \mathrm{~cm}$, ukuran yang luas jarang dijumpai. Insidensi NMKL diperkirakan 1 dari 20.000 hingga 500.000 pasien. Perempuan lebih sering ditemukan dibanding laki-laki, dengan perbandingan $3: 2 .^{2}$

Sampai saat ini NMKL dikatakan terjadi secara sporadik, dan hanya ada sedikit publikasi yang menulis tentang kemungkinan kelainan ini diturunkan secara herediter. Namun demikian, berdasarkan telaah kasus yang dilakukan oleh Danarti dkk. (2003), didapatkan 14 kasus dengan riwayat keluarga positif, sehingga diusulkan bahwa kelainan ini diturunkan secara paradominan. ${ }^{6}$ Pada kasus yang kami laporkan, tidak dijumpai riwayat keluarga dengan NMKL. Nevus melanositik kongenital disebabkan oleh kelainan genetik lokalisata yang menyebabkan proliferasi melanosit. Proliferasi abnormal terjadi

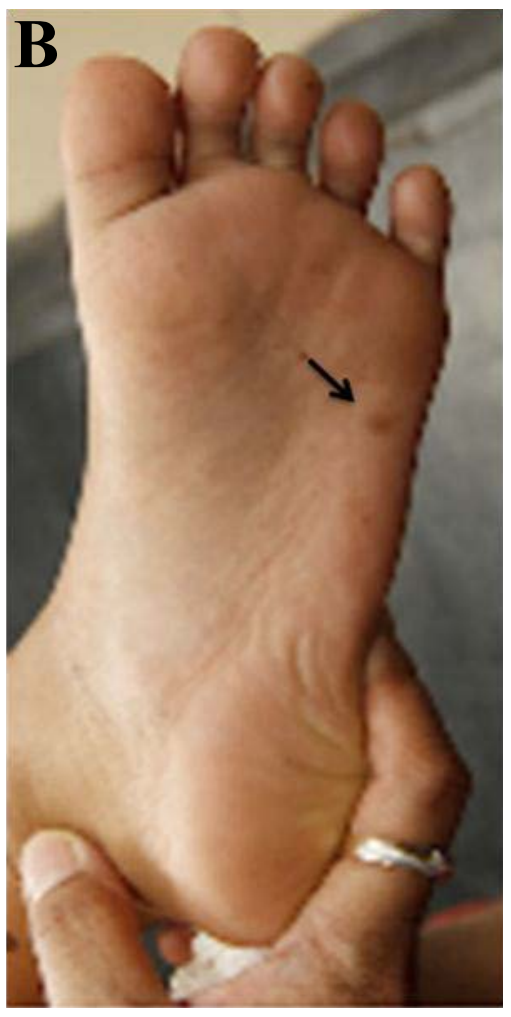

Gambar B. Pada telapak kaki kiri tampak makula hiperpigmentasi ukuran bervariasi 0,2 hingga $0,4 \mathrm{~cm}$, multipel, tersebar.

antara minggu ke-5 dan -24 kehamilan. Bila proliferasi dimulai saat awal perkembangan maka dapat terjadi NMK dengan ukuran medium dan luas dan pada beberapa kasus didapati pertumbuhan sel rambut. Bila proliferasi dimulai pada tahap akhir perkembangan setelah melanoblas bermigrasi dari neural crest ke kulit akan terjadi NMK kecil. Proto-oncogenes c-met dan c-kit berperan penting dalam perkembangan melanosit. Hepatocyte growth factor yang merupakan sebuah sitokin (messenger protein) yang meregulasikan proliferasi dan migrasi melanosit juga berperan penting dalam timbulnya NMK. 5,7

Lesi NMK dapat berbentuk bulat atau oval, bercak berpigmen kecoklatan, kehitaman, keabuan hingga kebiruan, dapat disertai pertumbuhan rambut di atasnya (hipertrikosis), permukaan dapat sedikit kasar ataupun menimbul, biasanya asimtomatik, namun beberapa dapat menimbulkan rasa gatal terutama pada lesi yang lebih luas. ${ }^{1,2}$ Gejala lainnya dapat berupa penurunan fungsi kelenjar sebasea dan ekrin. ${ }^{2}$ Beberapa klasifikasi NMK telah dikemukakan oleh banyak peneliti. Berdasarkan ukuran, NMK dibagi menjadi NMK kecil berdiameter $<1,5 \mathrm{~cm}$; NMK sedang dengan diameter 1,5-19.9 cm; dan NMK luas diameter $20 \mathrm{~cm} .{ }^{3}$ Klasifikasi tersebut dimodifikasi menjadi NMK kecil diameter $<1,5 \mathrm{~cm}$, NMK 
medium diameter 1,5-10 cm, NMK luas diameter 11-20 $\mathrm{cm}$, dan NMK raksasa $20 \mathrm{~cm}$. NMK raksasa ini dibagi menjadi beberapa subtipe yaitu G1 $(21-30 \mathrm{~cm})$, G2 (31$40 \mathrm{~cm})$, dan G3 $(>40 \mathrm{~cm}){ }^{8}$ Pada tahun 2013 beberapa peneliti mengkategorikan NMK menggunakan klasifikasi lesi berukuran kecil $(<1,5 \mathrm{~cm})$, lesi berukuran medium (M1: 1,5-10 cm, M2: $>10-20 \mathrm{~cm}$ ), lesi berukuran luas (L1: $>20-30 \mathrm{~cm}, \mathrm{~L} 2:>30-40 \mathrm{~cm}$ ), lesi berukuran raksasa (NMKR) (G1: $>40-60 \mathrm{~cm}, \mathrm{G} 2:>60 \mathrm{~cm}$ ), dan jumlah nevus satelit: $0,1-20,>20-50$ dan $>50$ lesi satelit. ${ }^{8}$

Nevus melanositik kongenital (NMK) luas dapat mengakibatkan peningkatan risiko terjadinya melanoma dengan persentase bervariasi antara 0 hingga $50 \%$. Melanoma dapat pula timbul pada lesi NMK kecil hingga medium yang tumbuh lebih superfisial dan pada lesi luas yang tumbuh lebih dalam. Risiko melanoma lebih sering dijumpai pada NMKL atau NMKR dengan predileksi tersering di trunkus dibandingkan dengan yang berlokasi di kepala atau ekstremitas. ${ }^{9-11}$ Nevus satelit dilaporkan pada pasien dengan melanoma kutan primer dengan persentase $91 \%$, namun tidak terdapat data yang menyebutkan melanoma kutan timbul pada nevus satelit atau pada NMKL. ${ }^{10}$ Insidensi terbanyak munculnya melanoma adalah pada usia 0-10 tahun. Sekitar 50-60\% melanoma kutan timbul pada kasus NMKR pada usia kurang dari 5 tahun. ${ }^{5}$ Dari data rekam medis pasien di New York University Medical Center pasien NMKL yang disertai melanoma tercatata sekitar $4,9 \%$ pasien. Sekitar 70\% melanoma terdiagnosis pada usia 3 tahun dan sisanya terdiagnosis pada usia 35 tahun atau lebih. Terdapat beberapa teori terjadinya melanoma pada NMKL. Salah satu teori yaitu peningkatan bermakna jumlah melanosit disertai degenerasi maligna. Teori lain menyatakan bahwa pada NMKL terjadi peningkatan persentase mutasi NRAS (70\%) serta rendah nya persentase mutasi BRAF (15\%). ${ }^{12}$ Risiko terjadinya melanoma maligna pada NMK kecil dan medium masih belum diketahui, namun secara umum risiko ini terjadi pada anak yang berusia sangat muda. Melanosit yang berasal dari NMKL menunjukkan perubahan kromosom BRAF onkogen yang diduga merupakan risiko terjadinya melanoma pada NMKL. ${ }^{10,12}$ Penelitian lain menyebutkan pula kemungkinan mutasi NRAS onkogene yang ditemukan pada melanoma kutan sebagai faktor risiko dalam pembentukan melanoma pada NMKL. ${ }^{9}$ Charbel dkk. (2014) menyebutkan terjadi mutasi NRAS pada NMKL $(94,7 \%)$ yang berperan menyebabkan perubahan ke arah keganasan. ${ }^{12}$ Deteksi awal terjadinya melanoma dapat dilihat dari perubahan ukuran, timbulnya papul atau nodul, dan atau ulserasi. ${ }^{10}$

Pasien dengan NMKL yang terdapat di sepanjang aksis posterior terutama dengan lesi satelit nevi melanositik berisiko lebih besar untuk berkembangnya gejala neurokutaneus melanosis (NM). ${ }^{13}$ Neurokutaneus melanosis merupakan sindrom yang jarang dijumpai. Pada NM terjadi proliferasi melanosit di sistem saraf pusat (otak dan medula spinalis) yang disertai NMK. ${ }^{3}$ Neuromelanosis (melanosis serebral) dapat terjadi pada NMK, yaitu terjadi kelainan kongenital saat morfogenesis pada ektodermal embrional yang ditandai dengan proliferasi melanositik (jinak atau ganas, nodular atau difus) dalam leptomening dan parenkim otak. ${ }^{14}$ Neurokutaneus melanosis dapat berpengaruh pada amigdala, serebrum, serebelum, pons, dan medula spinalis. Beberapa pasien menunjukkan gejala sebelum atau sekitar usia 2 tahun namun dapat juga timbul setelahnya. Gejala dapat berupa nyeri kepala, letargi, muntah berulang, dan fotofobia yang merupakan gejala akibat peningkatan tekanan intrakranial. Gejala lainnya dapat berupa hidrosefalus, kejang, cranial nerve palsies, penurunan sensorimotor, disfungsi pencernaan dan kandung kemih dan atau kelambatan perkembangan. Prognosis neuromelanosis buruk dengan angka mortalitas yang tinggi dibandingkan dengan pasien tanpa geja1a. ${ }^{2,5}$ Neurokutaneus melanosis dapat menyebabkan terjadinya epilepsi, namun kasus epilepsi tanpa penurunan fungsi saraf sangat jarang dijumpai. ${ }^{2}$

Insidensi NM pada pasien NMKR berkisar 2,5\% hingga 45\%. Faktor risiko NM berupa yaitu NMKR, laki-laki, terdapat nevus satelit atau NMK multipel dan lesi pada kepala, leher atau midline posterior. ${ }^{2}$ Penelitian oleh DeDavid dkk. (1996) menunjukkan bahwa dari 289 pasien NMKR, terdapat 33 pasien $(11,4 \%)$ dengan NM simtomatik dan pada 33 pasien tersebut sekitar $93,9 \%$ ditemukan nevus satelit. ${ }^{15}$

Kriteria diagnosis neurokutaneus melanosis yaitu: (1). Lesi ukuran luas dengan diameter $20 \mathrm{~cm}$ pada dewasa dan diameter $>9 \mathrm{~cm}$ pada bayi dan neonatus atau NMKR multipel (lesi $>3$ ) dengan melanosis meningeal atau melanoma; (2). Tidak terdapat bukti melanoma kutan; dan (3). Tidak terdapat bukti melanoma meningeal. ${ }^{16,17}$

Pemeriksaan radiologis, misalnya CT-scan dan magnetic resonance imaging (MRI) dapat digunakan untuk mencari keterlibatan neuromelanosis. Magnetic resonance imaging merupakan pilihan utama yang sebaiknya dilakukan pada 4 bulan pertama kehidupan. ${ }^{2}$

Tata laksana kasus NMK sebelum timbul melanoma bertujuan untuk menurunkan risiko melanoma kutan dan untuk alasan kosmetik. ${ }^{18}$ Tata laksana NMKL secara teknik lebih sulit dan terkadang untuk menghilangkan lesi secara menyeluruh tidak dapat dilakukan. Beberapa modalitas terapi yang dapat dilakukan pada NMK adalah eksisi, kuretase, dermabrasi, peeling kimia, cryotherapy, elektrosurgery, ablative laser, dan pigment-spesific laser. ${ }^{18}$ Eksisi yang dilakukan pada NMKL dapat menurunkan risiko melanoma kutan walaupun beberapa peneliti mengemukakan terjadinya melanoma kutan 
berulang pada pasien yang telah dilakukan eksisi atau beberapa kali terapi bedah lainnya misalnya mikrodermabrasi. Pendapat lain menyebutkan risiko melanoma kutan berkurang pada pasien yang dilakukan eksisi namun pada kasus melanoma ekstrakutan terutama pada pasien neurokutaneus melanosis yang simtomatik, risiko melanoma tidak dapat diturunkan. ${ }^{10}$

Neurokutaneus melanosis simptomatik jarang dijumpai dan prognosis lebih buruk dibandingkan dengan neurokutaneus melanosis asimtomatik, umumnya pasien dengan manifestasi kelainan saraf $70 \%$ akan meninggal sebelum usia 10 tahun., ${ }^{2,10}$

Pada pasien kami didapatkan bercak hiperpigmentasi - keabuan sejak lahir, sebagian dengan bercak eritem di tengahnya dengan hipertrikosis di atasnya, berbatas tegas, multipel, diskret, ukuran bervariasi dari $10 \mathrm{~cm}$ hingga $>20 \mathrm{~cm}$ pada telinga kiri hingga leher bagian kiri dan tengkuk, serta bokong. Pada wajah, kedua lengan dan tungkai, punggung, telapak kaki, punggung kaki tampak makula hingga bercak hiperpigmentasi, batas tegas, ukuran bervariasi 0,3 hingga $5 \mathrm{~cm}$, multipel, diskret. Anamnesis dan pemeriksaan fisis mendukung diagnosis

\section{DAFTAR PUSTAKA}

1. Levy R,Lara-CorralesI. Melanocytic nevi in children: A review. Pediatr Ann. 2016;45(8):e293-8.

2. Alikhan A, IbrahimiOA, EisenDB. Congenital melanocytic nevi: Where are we now? Part I. Clinical presentation, epidemiology, pathogenesis, histology, malignant transformation, and neurocutaneous melanosis. J Am Acad Dermatol. 2012;67(4):495 e1-17; quiz 512-4.

3. Bekiesinska-Figatowska M, Szczygielski O, Boczar M, Madzik J, Klepacka T, Michalak E, dkk. Neurocutaneous melanosis in children with giant congenital melanocytic nevi. Clin Imaging. 2014;38(2):79-84.

4. Sibbald C, Randhawa H, Branson H, Pope E. Neurocutaneous melanosis and congenital melanocytic naevi: A retrospective review of clinical and radiological characteristics. Br J Dermatol. 2015;173(6):1522-4.

5. Makkar HS, FriedenIJ. Congenital melanocytic nevi: An update for the pediatrician. Curr Opin Pediatr. 2002;14(4):397403.

6. Danarti R, KönigA, HappleR. Large congenital melanocytic nevi may reflect paradominant inheritance implying allelic loss. Eur J Dermatol. 2003;13(5):430-2.

7. Price HN. Congenital melanocytic nevi: Update in genetics and management. Curr Opin Pediatr. 2016;28(4):476-82.

8. Viana AC, GontijoB, BittencourtFV. Giant congenital melanocytic nevus. An Bras Dermatol. 2013;88(6):863-78.

9. Kinsler VA, O'Hare P, Bulstrode N, Calonje JE, Chong WK, Hargrave D, dkk. Melanoma in congenital melanocytic naevi. Br J Dermatol. 2017;176(5):1131-1143.

10. Shah KN. The risk of melanoma and neurocutaneous melanosis associated with congenital melanocytic nevi. Semin Cutan Med Surg. 2010;29(3):159-64.
NMKL. Pada kasus ini tidak didapatkan gejala neurokutaneus melanosis secara klinis, namun pelacakan untuk neurokutaneus melanosis perlu dilakukan. Hasil computed electroenchepalograph dan brain mapping (CEEG dan BM) tidak ditemukan gelombang epileptiform, tetapi ditemukan gambaran perlambatan difuse background activity. Pada kasus tidak didapatkan perubahan ukuran yang cepat, perubahan bentuk lesi yang mengarah pada melanoma malignum namun observasi masih perlu dilakukan. Pasien tidak datang kembali untuk kontrol, sehingga tidak dapat diikuti perkembangannya.

\section{SIMPULAN}

Telah dilaporkan satu kasus nevus melanositik kongenital luas. Diagnosis ditegakkan berdasarkan anamnesis, pemeriksaan fisik, dan pemeriksaan penunjang. Nevus melanositik kongenital luas pada kepala dan leher yang disertai nevus satelit sering dihubungkan dengan neurokutaneus melanositik. Pada kasus ini tidak didapatkan gejala neurokutaneus melanosis secara klinis namun pelacakan terhadap gejala neurokutaneus melanosis serta observasi terhadap kemungkinan terjadinya melanoma.

11. Vourc'h-Jourdain M, Martin L, Barbarot S. Large congenital melanocytic nevi: Therapeutic management and melanoma risk: A systematic review. J Am Acad Dermatol. 2013;68(3):493-8 e1-14.

12. Charbel C, Fontaine RH, Malouf GG, Picard A, Kadlub N, El-Murr N, dkk. NRAS mutation is the sole recurrent somatic mutation in large congenital melanocytic nevi. J Invest Dermatol. 2014;134(4):1067-74.

13. Scattolin MA, Lin J, Peruchi MM, Rocha AJ, Masruha MR, Vilanova LC.Neurocutaneous melanosis: Follow-up and literature review. J Neuroradiol. 2011;38(5):313-8.

14. Taylor DR, Wait SD, Wheless JW, Boop FA. Amygdalar neuromelanosis intractable epilepsy without leptomeningeal involvement. J Neurosurg Pediatr. 2013;12(1):21-4.

15. DeDavid M, Orlow SJ, Provost N, Marghoob AA, Rao BK, Wasti Q, dkk. Neurocutaneous melanosis: Clinical features of large congenital melanocytic nevi in patients with manifest central nervous system melanosis. J Am Acad Dermatol. 1996;35(4):529-38.

16. Kadonaga JN, FriedenIJ. Neurocutaneous melanosis: Definition and review of the literature. J Am Acad Dermatol.1991;24(5 Pt 1):747-55.

17. Makkar HS,FriedenIJ. Neurocutaneous melanosis. Semin Cutan Med Surg. 2004;23(2):138-44.

18. Ibrahimi OA, AlikhanA, Eisen DB. Congenital melanocytic nevi: Where are we now? Part II. Treatment options and approach to treatment. J Am Acad Dermatol. 2012;67(4):515 e1-13; quiz 528-30. 